\title{
BMJ Open Do perceived job insecurity and annoyance due to air and noise pollution predict incident self-rated poor health? A prospective analysis of independent and joint associations using a German national representative cohort study
}

\author{
Natalie Riedel, ${ }^{1}$ Adrian Loerbroks, ${ }^{2}$ Gabriele Bolte, ${ }^{1}$ Jian Li ${ }^{2}$
}

To cite: Riedel N,

Loerbroks A, Bolte G, et al. Do perceived job insecurity and annoyance due to air and noise pollution predict incident self-rated poor health? A prospective analysis of independent and joint associations using a German national representative cohort study. BMJ Open 2017;7:e012815. doi:10.1136/bmjopen-2016012815

- Prepublication history for this paper is available online. To view these files please visit the journal online (http://dx.doi.org/10.1136/ bmjopen-2016-012815).

Received 26 May 2016 Revised 4 October 2016 Accepted 10 November 2016

CrossMark

For numbered affiliations see end of article.

Correspondence to Dr Natalie Riedel; nriedel@uni-bremen.de

\section{ABSTRACT}

Background: Current economic and social change has contributed to increasing job insecurity and trafficrelated pollution in residential areas. Both job insecurity and exposure to noise and air pollution are known determinants of population health and can concur in peoples' lives. This may hold true particularly for socially disadvantaged subpopulations. Nevertheless, the potential independent and joint links of those exposures to health have been rarely examined so far. We aimed to contribute to the scarce body of evidence. Methods: Information on perceived job insecurity and exposures to noise and air pollution as expressed by annoyance as well as on self-rated health were gathered from 2 waves of the population-based German Socio-Economic Panel (2009 and 2011, $\mathrm{N}=6544$ ). We performed multivariable Poisson regression to examine the independent and joint risk of poor health in 2011 by perceived job insecurity and annoyance due to noise and air pollution in 2009.

Results: After the 2-year follow-up in 2011, 571 $(8.7 \%)$ participants rated their health as poor. The risk of reporting incident poor health was increased by roughly $40 \%$ in employees reporting high versus low perceived job insecurity and annoyance due to noise and air pollution, respectively. This risk increased when both exposures were present at higher levels (risk ratio $=1.95$ (1.49 to 2.55)).

Conclusions: Work-related and environmental exposures may accumulate and have a joint health impact. Elaboration on the link between occupational and residential exposures is warranted in the light of their concurrence and their implications for health inequities.

\section{INTRODUCTION}

With labour markets growing more and more unpredictable, perceptions of job

\section{Strengths and limitations of this study}

- Both perceived job insecurity and annoyance due to traffic-related exposures have advanced as major risk factors for population health. Although they are likely to concur, their independent and joint health effects have not been studied yet.

- In this prospective, population-based study, we could document that perceived job insecurity and annoyance due to noise and air pollution show both independent and joint associations with incident self-rated poor health.

- Subjective measures of job insecurity and exposure to noise and air pollution indicate indirect perceptional pathways of psychological stress. Thus, we could not detect direct physiological effects due to the objective intractability of these two exposures.

- Our study underlines the need to integrate workrelated and environmental research both conceptually and empirically.

insecurity have increased across European Union member states and beyond. ${ }^{1-3}$ Longitudinal studies have consistently shown that high job insecurity predicts poor health outcomes. ${ }^{4}$

In addition to perceived job insecurity, other components of current economic and social change (eg, job specialisation, globalisation, double breadwinner households) are associated with an increase in transportation in the European Union during the past decades. $^{5-7} \mathrm{~A}$ further increase in freight traffic is still expected despite the economic crisis in 2009. ${ }^{7}$ Motorised transportation constitutes a major cause for chronic, local 
exposure to noise and air pollution. ${ }^{589}$ Traffic-related noise and ultrafine particulate matter air pollution have been identified as the most important environmental challenges in Western European cities, ${ }^{8}$ which have been illustrated by estimating an enormous number of healthy life years lost from noise annoyance (ie, 654000 disability-adjusted life-years) ${ }^{9}$

In view of these current developments, it is plausible to assume that job insecurity and traffic-related exposures are likely to concur in residential and occupational contexts. This may hold true particularly for socially disadvantaged subpopulations. ${ }^{3} 10$ This notion is in line with social epidemiological models on health determinants and inequities, which highlight the accumulation of exposures across contexts. ${ }^{11} 12$ However, there is little research linking different types of work-related and residential exposures to health in one single study, although there are studies on traffic-related air and noise pollution modelling peoples' (outdoor) exposures in both occupational and residential contexts (eg, see ref. ${ }^{13}$ for a study on asthma and ref. ${ }^{14}$ for a study on blood pressure). We are aware of only one cross-sectional study suggesting an accumulation of physiological impacts of objective residential and occupational noise exposure and/or self-reported job strain on myocardial infarction while adjusting for air pollution. ${ }^{15}$

In the current study, we aim to contribute to this scarce body of evidence by examining the independent and joint associations of perceived job insecurity and annoyance due to noise and air pollution with self-rated poor health in a representative sample of the German working population. In doing so, we focus on indirect psychological pathways from these two contextual exposures to health and recur to parallel lines of argumentation within both occupational health and environmental psychology (eg, Conversation of Resources Theory by Hobfoll in refs. ${ }^{16},{ }^{17}$ or the Appraisal Theory by Lazarus and Folkman in refs. ${ }^{18-20}$ ). That is, we assume that perceived job insecurity and annoyance due to noise and air pollution in the residential area may share the same stress-based mechanism to produce poor health: perceived uncontrollability of exposure and its feared or unwanted consequences of resource loss, (mal-)adaptive behavioural responses implying (vain) resource investment and subsequent physiological costs and, finally, adverse health outcomes.

\section{METHODS}

\section{Study population and study sample}

We retrieved our study sample from the German Socio-Economic Panel (GSOEP), a national survey conducted annually by face-to-face interviews in representatively selected households since $1984 .{ }^{21}$ All household members aged 18+ were eligible for participation after giving their informed consent. Our prospective, complete case analysis is primarily based on data from the 2009 and 2011 waves covering topics such as work and employment (including job insecurity) in the individual questionnaire as well as housing and environmental exposures in the household questionnaire (including annoyance due to noise and air pollution). The household questionnaire was answered by the household member who felt most competent with regard to household matters (called 'household representative' in the GSOEP). Using the household code as a key variable, household-level information was added to the data on each individual in the household. Given our study aim, we restricted our analysis to participants employed (total $\mathrm{N}=11381$, complete cases $\mathrm{N}=9493,83.4 \%$ ) in our baseline in 2009 and still remaining in the GSOEP in our follow-up in $2011(\mathrm{~N}=7339$, response rate $=77.5 \%$ ). Further, we considered only those who were in good health in 2009 (see measures below). Thus, our study sample included 6544 participants (89.2\% of 7339) living in 4626 households.

The GSOEP is compliant with national laws. It is evaluated by the German Council of Science and Humanities at the German Institute for Economic Promotion (DIW) and is explicitly intended for epidemiological analyses. ${ }^{21}$

\section{Exposure and outcome measures}

At our baseline in 2009, perceived job insecurity was assessed by participants' anticipated probability of losing their job within the next 2 years on a $10 \%$ decrement scale. $^{22} 23$ A cut-off point of $\geq 50 \%$ on this scale was found to be both conceptually meaningful and statistically efficient to differentiate between perceived lower and higher job insecurity ${ }^{24}$ (we call the participants with perceived higher job insecurity shortly 'job insecure').

Annoyance due to noise and air pollution in the residential area was derived from the household representatives' reporting of the degree of disturbance. Though not source-specific, we may regard these variables as proxy for perceived exposures related to traffic as main emission source. Household-specific disturbance values were assigned to the individuals belonging to the same household at the respective address. While rated separately on five-point Likert scales, disturbances due to noise and air pollution were highly correlated $\left(\mathrm{r}_{\mathrm{s}}=0.67\right)$. In line with an earlier GSOEP study, ${ }^{25}$ we summed up the values of both items, with higher values signalling a higher degree of disturbance (called hereafter 'environmental annoyance'). We dichotomised this sum scale whose scores ranged from 2 (not at all affected by noise and air pollution) to 10 (very strongly affected by noise and air pollution) at the cut-off point $\geq 5$. Thus, environmental annoyance was assumed to be present at higher levels in 2009 if households perceived disturbance due to noise and/or due to air pollution as being just bearable, strong or very strong (we call these participants shortly 'environmentally annoyed'). This cut-off point served both statistical efficiency and empirical relevance. Sensitivity analyses using two alternative cut-off points $(\geq 4$ and $\geq 6$ ) did not reveal substantial differences in effect sizes of environmental annoyance in relation to self-rated poor health (see Statistical analyses section 
below). Similar cut-off points have been employed to indicate higher levels of noise annoyance on five-point Likert scales in previous population-based studies. ${ }^{17} 2627$

Finally, the dichotomised information on job insecurity and environmental annoyance was combined in one composite variable with four exposure categories, with 'perceived lower job insecurity and lower environmental annoyance' as the reference group as compared with the categories 'perceived higher job insecurity and lower environmental annoyance', 'perceived lower job insecurity and higher environmental annoyance' and 'perceived higher job insecurity and higher environmental annoyance'.

We inferred our incident outcome variable from one single question making participants rate their health on a five-point Likert scale. Those who reported their health as 'not so good' or 'bad' were defined as having poor health.

\section{Potential confounders}

Besides age and gender, we considered educational attainment (continuous, as measured by years of formal education), personal net income (continuous, logtransformed for multivariable analysis due to skewness), marital status and contract type (permanent as opposed to non-permanent contract) as indicators of participants' sociodemographic and economic position at our baseline in 2009. Health-related behaviour was mostly measured in the wave prior to our baseline by current smoking, alcohol consumption, physical exercise and body mass index. ${ }^{24}$

\section{Statistical analyses}

Statistical differences in potential confounders between levels of perceived job insecurity and environmental annoyance were determined by Student's t-test or $\chi^{2}$ test. Associations of perceived job insecurity and environmental annoyance in 2009 with an incident self-rated poor health in 2011 were quantified by risk ratios with $95 \%$ CIs using Poisson regression with a log-link function. To account for household clustering, we integrated a sandwich variance estimator in the Poisson regression models by means of the household code as a cluster identifier. ${ }^{28}$ First, we simultaneously entered perceived job insecurity and environmental annoyance in 2009 as independent predictors of self-rated poor health in 2011. Second, we estimated their joint effects as measured by the composite exposure variable. In both regression series, we adjusted for age and gender in model I as well as for sociodemographic and economic position and health-related behaviour in model II in order to assess robustness of associations. Statistical analyses were performed using SAS, V.9.4

\section{RESULTS}

On average, 1.4 persons lived in one household in 2009, with the household size ranging from 1 to 5 individuals.
One in five participants reported higher job insecurity or higher environmental annoyance. Both exposures co-occurred in $373(5.7 \%)$ participants; among job insecure participants, odds of being environmentally annoyed were elevated by $50 \%$ (OR $1.50,95 \%$ CI 1.27 to 1.67). Characteristics of the study sample stratified by the two levels of perceived job insecurity and environmental annoyance are shown in table 1 . Lower personal net income levels, as well as unmarried and separated/ divorced/widowed status and non-permanent contracts, were more prevalent among participants characterised by perceived higher job insecurity or higher environmental annoyance. Job insecure participants were 2 years younger on average and more often lower educated. Overweight and obesity as well as physical inactivity were more common among job insecure participants, whereas the opposite was true for regular alcohol consumption. No clear behavioural pattern could be observed for the two levels of environmental annoyance.

After the 2-year follow-up in 2011, 571 (8.7\%) participants rated their health as poor. Three hundred and five $(53.4 \%)$ of these incident cases were female. Table 2 displays a bivariate association between higher levels of perceived job insecurity or environmental annoyance and incident self-rated poor health.

As evident in table 3, job insecure participants and environmentally annoyed participants had comparable risks of reporting incident poor health. The excess risk for each exposure was estimated to increase by $40 \%$ in the first Poisson regression series on independent effects. In the second series on joint effects, the composite exposure variable confirmed the main effects of both variables in the exposure categories 'perceived higher job insecurity and lower environmental annoyance' and 'perceived lower job insecurity and higher environmental annoyance'. The joint exposure to perceived higher job insecurity and higher environmental annoyance at baseline was associated with a double excess risk of selfrated poor health 2 years later. Associations remained stable throughout the adjustment procedure as shown by models I and II.

\section{DISCUSSION}

In line with earlier population-based studies on either job insecurity ${ }^{29} 30$ or annoyance due to noise pollution and/or air pollution, ${ }^{17} 25$ we observed positive associations with self-rated poor health. What is more, we could document that these exposures, if examined based on the same database, show both statistically independent and joint associations with incident self-rated poor health. Our findings of additive associations are similar to the patterns observed in ref. ${ }^{15}$ on myocardial infarction, though comparability is limited due to a different work-related exposure (job strain) and different measurements of traffic-related exposure(s).

Based on the Appraisal Theory and Conservation of Resources Theory, which are used in occupational 
Table 1 Characteristics of the study population at baseline in $2009(\mathrm{~N}=6544)$ stratified by levels of perceived $\mathrm{Jl}$ and of EA in 2009

\begin{tabular}{|c|c|c|c|c|c|c|}
\hline Characteristics, n (\%) & $\begin{array}{l}\text { Lower JI } \\
5055 \text { (77.25) }\end{array}$ & $\begin{array}{l}\text { Higher JI } \\
1489 \text { (22.75) }\end{array}$ & p Value & $\begin{array}{l}\text { Lower EA } \\
5227(79.87)\end{array}$ & $\begin{array}{l}\text { Higher EA } \\
1317(20.13)\end{array}$ & p Value \\
\hline \multicolumn{7}{|l|}{ Continuous variables, mean (SD) } \\
\hline Age (years) & $43.71(10.85)$ & $41.68(11.19)$ & $<0.0001$ & $43.26(10.90)$ & $43.18(11.18)$ & 0.8140 \\
\hline Education (years) & $13.12(2.83)$ & $12.37(2.48)$ & $<0.0001$ & $12.94(2.77)$ & $13.00(2.79)$ & 0.4329 \\
\hline Personal net income per month $(€)$ & 1835 (1389) & 1375 (1067) & $<0.0001$ & 1757 (1359) & $1623(1238)$ & 0.0112 \\
\hline \multicolumn{7}{|l|}{ Categorical variables, n (\%) } \\
\hline Female & 2407 (47.62) & $747(50.17)$ & 0.0833 & $2497(47.77)$ & 657 (49.89) & 0.1698 \\
\hline \multicolumn{7}{|l|}{ Marital status } \\
\hline Unmarried & $1202(23.78)$ & $441(29.62)$ & $<0.0001$ & $1268(24.26)$ & $375(28.47)$ & 0.0028 \\
\hline Separated/divorced/widowed & $444(8.78)$ & $142(9.54)$ & & $461(8.82)$ & $125(9.49)$ & \\
\hline Married & 3409 (67.44) & $906(60.85)$ & & 3498 (66.92) & 817 (62.03) & \\
\hline Non-permanent contract & $1116(22.08)$ & $475(31.90)$ & $<0.0001$ & $1237(23.67)$ & $354(26.88)$ & 0.0151 \\
\hline Current smoking & $1463(28.94)$ & $504(33.85)$ & 0.0003 & $1561(29.86)$ & $406(30.83)$ & 0.4955 \\
\hline Regular alcohol consumption & $1028(20.34)$ & $260(17.46)$ & 0.0142 & $1045(19.99)$ & $243(18.45)$ & 0.2086 \\
\hline \multicolumn{7}{|l|}{ Physical exercise } \\
\hline Never & $1279(25.30)$ & $440(29.55)$ & $<0.0001$ & $1390(26.59)$ & 329 (24.98) & 0.0536 \\
\hline Less than & $1517(30.01)$ & 505 (33.92) & & $1579(30.21)$ & $443(33.64)$ & \\
\hline At least once a $v$ & 2259 (44.69) & $544(36.53)$ & & 2258 (43.20) & 545 (41.38) & \\
\hline \multicolumn{7}{|l|}{ Body mass index } \\
\hline Normal & 2489 (49.24) & 725 (48.69) & 0.1616 & 2531 (48.42) & $683(51.86)$ & 0.0606 \\
\hline Overweight & 1859 (36.78) & 527 (35.39) & & 1940 (37.11) & $446(33.86)$ & \\
\hline Obesity & 707 (13.99) & 237 (15.92) & & $756(14.46)$ & $188(14.27)$ & \\
\hline
\end{tabular}

Differences were determined by Student's t-test or $\chi^{2}$ test.

$\mathrm{EA}$, environmental annoyance; JI, job insecurity.

health research and environmental psychology (eg, studies of refs. ${ }^{16},{ }^{18}$ and reviews of refs. ${ }^{2},{ }^{4}$ for occupational health research as well as studies of refs. ${ }^{17}, 19,20$ and reviews of refs. ${ }^{31},{ }^{32}$ for environmental psychological approaches), we suggest that both associations may originate from low perceived control over resource maintenance. Psychological stress may result from the experience and subsequent expectation that any efforts and resources spent to prevent resource loss fail to yield the desired or any effect at all. Job insecurity has been conceptually linked to 'powerlessness to exercise workplace rights' ${ }^{2}$ and unfavourable physical and psychosocial work conditions undermining employees' capacity to draw and replenish resources. Annoyance due to noise and air pollution has been conceived as a psychological stress reaction to a lack of coping resources needed to counter the perceived environmental threat to health, which may likewise result in powerlessness to claim citizens' rights to environmental health. Moreover, stress may arise from resource depletion, since employees blindly start investing resources in coping strategies associated with high physiological costs and negative (subjective) health outcomes, like overworking in order not to lose the job ${ }^{2}$ or withdrawing from work while ruminating $^{4} 18$ or fostering avoidance and comforting cognitions while suffering from high levels of stress due to noise. ${ }^{19}$

These theoretical considerations imply a shared stressbased mechanism, as we showed that perceived job insecurity and annoyance due to noise and air pollution are each associated with incident self-rated poor health and that the strength of any such relationship further increases in case of a joint exposure. In view of the co-occurrence of high job insecurity and high environmental annoyance and their links to health in our sample, we should further elaborate on the theoretical linkages between residential and occupational contexts. Having been discussed in work stress ${ }^{33} 34$ and noise

Table 2 Incident self-rated poor health in $2011(\mathrm{~N}=571,8.7 \%$, out of 6544$)$ stratified by levels of perceived $\mathrm{JI}$ and of $\mathrm{EA}$ in 2009

\begin{tabular}{|c|c|c|c|c|c|c|}
\hline Characteristic, n (\%) & $\begin{array}{l}\text { Lower Jl } \\
5055 \text { (77.25) }\end{array}$ & $\begin{array}{l}\text { Higher Jl } \\
1489(22.75)\end{array}$ & p Value & $\begin{array}{l}\text { Lower EA } \\
5227(79.87)\end{array}$ & $\begin{array}{l}\text { Higher EA } \\
1317(20.13)\end{array}$ & p Value \\
\hline $\begin{array}{l}\text { Incident self-rated poor } \\
\text { health }\end{array}$ & 404 (7.99) & $167(11.22)$ & $<0.0001$ & $416(7.96)$ & 155 (11.77) & $<0.0001$ \\
\hline
\end{tabular}

Differences were determined by $\chi^{2}$ test.

$E A$, environmental annoyance; JI, job insecurity. 
Table 3 Independent and joint associations of $\mathrm{JI}$ and EA with incident self-rated poor health (RRs and $95 \% \mathrm{Cl}$ )

\begin{tabular}{|c|c|c|}
\hline Independent effects of $\mathrm{JI}$ and EA & Model I & Model II \\
\hline \multicolumn{3}{|l|}{$\mathrm{n}(\%)$} \\
\hline Lower JI (ref) 5055 (77.25) & 1 & 1 \\
\hline Higher JI 1489 (22.75) & $1.43(1.20$ to 1.69$)$ & 1.37 (1.16 to 1.63$)$ \\
\hline Lower EA (ref) 5227 (79.87) & 1 & 1 \\
\hline Higher EA 1317 (20.13) & $1.43(1.20$ to 1.70$)$ & $1.44(1.21$ to 1.71$)$ \\
\hline Joint effects of $\mathrm{JI}$ and EA & Model I & Model II \\
\hline \multicolumn{3}{|l|}{$\mathrm{n}(\%)$} \\
\hline Lower Jl+lower EA (ref) 4111 (68.82) & 1 & 1 \\
\hline Higher Jl+lower EA 1116 (17.05) & $1.44(1.17$ to 1.77$)$ & $1.39(1.13$ to 1.71$)$ \\
\hline Lower JI+higher EA 944 (14.43) & $1.44(1.17$ to 1.79$)$ & $1.46(1.18$ to 1.81$)$ \\
\hline Higher Jl+higher EA 373 (5.70) & 2.07 (1.54 to 2.64$)$ & 1.95 (1.49 to 2.55$)$ \\
\hline
\end{tabular}

Model I: adjustment for age and gender.

Model II: model I additionally adjusted for education, income, marital status, contract type, smoking, alcohol consumption, physical exercise and body mass index.

$\mathrm{Cl}$, confidence interval; EA, environmental annoyance; JI, job insecurity; RR, risk ratio.

research, ${ }^{19} 35$ the Cognitive Activation Theory of Stress (CATS) ${ }^{36} 37$ is a valuable complementary approach to understand the potential spillover effects of exposures from different contexts. This psychobiological theory posits that stress-induced pathophysiological processes are shaped by behavioural outcome expectancies individuals have learnt in response to stress stimuli. The resulting physiological activation level may influence individuals' resilience to future exposures from both contexts. If individuals have learnt to attribute the perceived exposure to job insecurity and noise and air pollution to external, intractable causes, they may develop no control or negative expectancies, that is, generalised helplessness and hopelessness. These types of outcome expectancies can cause pathophysiological changes. In contrast, a positive outcome expectancy in terms of generalised self-efficacy is linked to reduced physiological activation and improved health. That is, a positive behavioural outcome expectancy acquired in the residential context might help a resident survive in the occupational context, whereas threats to an employee's resources in the occupational context could affect her agency and health in the residential context due to no control or negative outcome expectancies.

The results for the composite exposure variable revealed that the relative absence (or lower values) of one exposure does not reduce the vulnerability to the other remaining exposure. It seems promising for future research to address resources that may exert protective effects in occupational and residential contexts and play a key role in intervention strategies aiming to reduce health inequities. Such resources may be personal (like CATS-positive outcome expectancy, perceived external employability in the face of job insecurity ${ }^{16}$ or selection, optimisation and compensation strategies in the face of uncontrollability feelings arising from effort-reward imbalance ${ }^{38}$ ) or contextual (like green areas and soundscapes allowing for relaxation and restoration ${ }^{39} 40$ or area-wide improvements rendering neighbourhood perception more positive ${ }^{41}$ ) or both.

Linking up with social determinants of health, a recent conceptual model from occupational health research presents precarious employment to influence health via material deprivation including residential neighbourhood quality. ${ }^{2}$ The differences in personal net income by levels of perceived job insecurity and environmental annoyance in our study sample may give a vague indication of this pathway, although we could not disclose the causal sequence of job insecurity and residential exposures to noise and air pollution.

It is a shortcoming of our study that information on annoyance due to noise and air pollution was not available in the individual questionnaire. Thus, we had to rely on the household representatives' rating. Consequently, the interpretation of our findings may be somewhat hampered, since our environmental annoyance variable is probably influenced by the selection of the household representative at home, her or his consideration of other household members' environmental perceptions and health as well as the presence or absence of household members during the interview.

Furthermore, we could use subjective measures of work-related and environmental exposures only. These indicate indirect perceptional pathways of psychological stress, whereas direct physiological effects due to the objective intractability of job insecurity as well as of air and noise pollution cannot be detected. Chronic exposure to ultrafine particulate matter and road traffic noise at night time was recently estimated to be independently related to an indicator of subclinical atherosclerosis. ${ }^{42}$ Objective conditions should be added in future analyses to fathom the interplay of direct and indirect pathways. ${ }^{17}$ It follows from CATS that sustained physiological activation may increase individuals' vulnerability to physical and chemical exposures like air and noise pollution (as is also suggested by socioenvironmental epidemiological frameworks of environmental health 
equity $\left.{ }^{43}{ }^{44}\right)$. Considering the potential spillover effects between occupational and residential contexts, future research should look for multiplicative interactions between stressors and resources from both contexts over time. However, we were not able to capture multiplicative effects with our data covering two points in time just 2 years apart.

It would be crucial to recognise differential patterns of confounding and moderating variables. For instance, bivariate associations of individual characteristics with perceived job insecurity were generally stronger than those with environmental annoyance. Again, it might reflect a drawback to our study that our environmental annoyance variable was measured at the household level, making direct comparisons of confounder distributions between the two levels of perceived job insecurity and environmental annoyance difficult. What is more, evidence for social inequalities in road traffic exposure largely varies by the indicators used, given the distributional discrepancy between road traffic noise and noise annoyance. ${ }^{26}$ In addition, we did not consider changes in exposure due to residential relocation or to regained job security between 2009 and 2011, which might have led to an underestimation of true associations between the two perceived exposures and self-rated poor health (as implied in ref. ${ }^{45}$ investigating the association of environmental disadvantage on self-rated poor health based on the GSOEP). However, perceived job insecurity has been found to have an after effect even after its cessation $^{29}$ and self-selection according to noise sensitivity and noise annoyance could not be corroborated in empirical studies. ${ }^{41}$ Furthermore, we did not have information on the perceived emission sources and other non-acoustical variables accounting for differences in noise annoyance, such as attitudes towards noise sources and trust in regulatory authorities. ${ }^{20} 31324647$

To the best of our knowledge, this is the first study to analyse the independent and joint associations of perceived job insecurity and annoyance due to noise and air pollution with incident self-rated poor health. If confirmed elsewhere, our findings call for more research integrating objectively intractable and subjectively uncontrollable exposures from different sectors to understand the multicausality of health (inequities) as implied by social epidemiological models on the social and societal determinants of health (see for an overview Krieger, ${ }^{12}$ eg).

\section{Author affiliations}

${ }^{1}$ Department of Social Epidemiology, Institute for Public Health and Nursing Research, University of Bremen, Bremen, Germany

${ }^{2}$ Institute for Occupational, Social, and Environmental Medicine, Center for Health and Society, Faculty of Medicine, University of Düsseldorf, Düsseldorf, Germany

Acknowledgements The authors are grateful to the German Institute for Economic Promotion (DIW), Berlin, for the Provision of the German Socio-Economic Panel (GSOEP) data employed for the current manuscript. NR is currently funded for the research project 'Transforming noise action planning into an instrument for more health equity' within the framework of the Institutional Strategy of the University of Bremen. This strategy is financed by the German Federal Government's and the Federal States' 'Excellence Initiative'.

Contributors NR wrote the draft of the manuscript. AL, GB and JL substantially contributed to the line of argumentation and revision of the manuscript. JL prepared the data. NR and JL conducted the statistical analyses.

Competing interests None declared.

Patient consent Obtained.

Ethics approval Obtained by the GSOEP.

Provenance and peer review Not commissioned; externally peer reviewed.

Data sharing statement The GSOEP is a public use data set that can be obtained from the German Institute for Economic Promotion (DIW), Berlin.

Open Access This is an Open Access article distributed in accordance with the Creative Commons Attribution Non Commercial (CC BY-NC 4.0) license, which permits others to distribute, remix, adapt, build upon this work noncommercially, and license their derivative works on different terms, provided the original work is properly cited and the use is non-commercial. See: http:// creativecommons.org/licenses/by-nc/4.0/

\section{REFERENCES}

1. van Gyes G, Szeker L. Impact of the crisis on working conditions in Europe. European Foundation for the Improvement of Living and Working Conditions; 2013 (4 May 2016); http://www.eurofound. europa.eu/observatories/eurwork/comparative-information/ impact-of-the-crisis-on-working-conditions-in-europe

2. Benach J, Vives A, Amable M, et al. Precarious employment: understanding an emerging social determinant of health. Annu Rev Public Health 2014;35:229-53.

3. Landsbergis PA, Grzywacz JG, LaMontagne AD. Work organization, Job insecurity, and occupational health disparities. Am J Ind Med 2014;57:495-515

4. de Witte H, Pienaar J, de Cuyper N. Review of 30 years of longitudinal studies on the association between job insecurity and health and well-being: is there causal evidence? Aust Psychol 2016;51:18-31.

5. European Commission. Roadmap to a single European transport area-towards a competitive and resource efficient transport system. 2011; (4 May 2016); (White Paper). http://eur-lex.europa.eu/ legal-content/EN/TXT/PDF/?uri=CELEX:52011DC0144\&from=EN

6. European Commission. EU transport in figures. Statistical pocketbook 2015. 2015; (4 May 2016); http://ec.europa.eu/transport/ facts-fundings/statistics/doc/2015/pocketbook2015.pdf

7. Umweltbundesamt [Transport in figures]. 2012; (4 May 2016); http:// www.umweltbundesamt.de/sites/default/files/medien/publikation/long/ 4364.pdf

8. European Environmental Agency. Noise in Europe; 2014 (4 May 2016); http://www.eea.europa.eu/publications/noise-in-europe-2014

9. World Health Organization Regional Office for Europe. Burden of disease from environmental noise. Quantification of healthy life years lost in Europe; 2011 (4 May 2016); http://www.who.int/quantifying ehimpacts/publications/e94888/en/

10. WHO Regional Office for Europe. Environmental health inequalities in Europe. Assessment report; 2012 (4 May 2016) http://www.euro. who.int/_data/assets/pdf_file/0010/157969/e96194.pdf

11. World Health Organisation Commission on Social Determinants of Health. Closing the gap in a generation. Health equity through action on the social determinants of health. 2008 (04 May 2016); http://apps.who.int/iris/bitstream/10665/43943/1/9789241563703 eng.pdf

12. Krieger N. Epidemiology and the people's health. Theory and context. New York: Oxford University Press.

13. Lindgren A, Björk J, Stroh E, et al. Adult asthma and traffic exposure at residential address, workplace address, and self-reported daily time outdoor in traffic: a two-stage case-control study. BMC Public Health 2010;10:716.

14. Méline J, Van Hulst A, Thomas F et al. Road, rail, and air transportation noise in residential and workplace neighborhoods and blood pressure (RECORD Study). Noise Health 2015;17:308-19.

15. Selander J, Bluhm G, Nilsson M, et al. Joint effects of job strain and road-traffic and occupational noise on myocardial infarction. Scand 
J Work Environ Health 2013;39:195-203. http://doi.org/10.5271/ sjweh.3324

16. de Cuyper N, Mäkikangas A, Kinnunen U, et al. Cross-lagged associations between perceived external employability, job insecurity, and exhaustion: testing gain and loss spirals according to the conservation of resources theory. J Org Behav 2012; 33:770-88.

17. Riedel N, Köckler H, Scheiner J, et al. Objective exposure to road traffic noise, noise annoyance and self-rated poor health-framing the relationship between noise and health as a matter of multiple stressors and resources in urban neighbourhoods. J Environ Plann Manage 2015;58:336-56.

18. van der Elst T, De Cuyper N, Baillien E, et al. Perceived control and psychological contract breach as explanations of the relationships between job insecurity, job strain and coping reactions: towards a theoretical integration. Stress Health 2016;32:100-16.

19. van Kamp I. Coping with noise and its health consequences. Groningen, The Netherlands: The University of Groningen, 1990.

20. Kroesen M, Molin EJE, van Wee B. Testing a theory of aircraft noise annoyance: a structural equation analysis. J Acoust Soc Am 2008;123:4250-60.

21. Schupp J. [The Socioeconomic Panel (SOEP)]. Bundesgesundheitsblatt Gesundheitsforschung Gesundheitsschutz 2012;55:767-74.

22. Bethge M, Radoschewski FM, Muller-Fahrnow W. [Job insecurity as risk for adverse health effects amongst German workers: a cohort study]. Gesundheitswesen 2008;70:381-6.

23. Muenster E, Rueger $\mathrm{H}$, Ochsmann E, et al. Association between overweight, obesity and self-perceived job insecurity in German employees. BMC Public Health 2011;11:162.

24. Loerbroks A, Bosch JA, Douwes J, et al. Job insecurity is associated with adult asthma in Germany during Europe's recent economic crisis: a prospective cohort study. $J$ Epidemiol Community Health 2014:68:1196-9.

25. Pollack CE, von dem Knesebeck O, Siegrist J. Housing and health in Germany. J Epidemiol Community Health 2004:58:216-22.

26. Riedel N, Scheiner J, Müller G, et al. Assessing the relationship between objective and subjective indicators of residential exposure to road traffic noise in the context of environmental justice. J Environ Plann Manage 2014;57:1398-421

27. Kohlhuber M, Mielck A, Weiland SK, et al. Social inequality in perceived environmental exposures in relation to housing conditions in Germany. Environ Res 2006;101:246-55.

28. Zou G, Donner A. Extension of the modified Poisson regression model to prospective studies with correlated binary data. SMM Res 2011;22:661-70.

29. Ferrie JE, Shipley MJ, Stansfeld SA, et al. Effects of chronic job insecurity and change in job security on self reported health, minor psychiatric morbidity, physiological measures, and health related behaviours in British civil servants: the Whitehall II study. J Epidemiol Community Health 2002;56:450-4.
30. Lazlo KD, Pikhart $\mathrm{H}$, Kopp MS et al. Job insecurity and health: a study of 16 European countries. Soc Sci Med 2010;70: 867-74.

31. Job RFS. The influence of subjective reactions to noise on health effects of the noise. Environ Int 1996;22:93-104. http://doi.org/10. 1016/0160-4120(95)00107-7

32. Stallen PJM. A theoretical framework for environmental noise annoyance. Noise Health 1999;1:69-79.

33. Kristenson M, Eriksen HR, Sluiter JK, et al. Psychobiological mechanisms of socioeconomic differences in health. Soc Sci Med 2004;58:1511-22.

34. Ree E, Odeen M, Eriksen HR, et al. Subjective health complaints and self-rated health: are expectancies more important than socioeconomic status and workload? IJBM 2014;21:411-20.

35. Klæboe R. Noise and health-annoyance and Interference. In Nriagu JO, ed. Encyclopedia of environmental health. Amsterdam, London: Elsevier Science, 2011: 152-63.

36. Ursin H, Eriksen HR. The cognitive activation theory of stress. Psychoneuroendocrinology 2004;29:567-92.

37. Ursin H, Eriksen HR. Cognitive activation theory of stress (CATS). Neurosci Biobehav Rev 2010;34:877-81.

38. Shang L, Riedel N, Loerbroks A, et al. The association between effort-reward imbalance and depressive symptoms is modified by selection, optimization, and compensation strategy. J Occup Environ Med 2015;57:1222-7.

39. Ward Thompson C, Roe J, Aspinall P et al. More Green space is linked to less stress in deprived communities: Evidence from salivary cortisol patterns. Landscape Urban Plann 2012;105:221-9.

40. van Kamp I, Klaeboe R, Brown AL, et al. Soundscapes, human restoration and quality of life. In: Kang J, Schulte-Fortkamp, eds. Soundscape and the built environment. Abdington, UK: CRC Press, Taylor \& Francis Group, 43-68.

41. Brown AL, van Kamp I. Response to a change in transport noise exposure: competing explanations of change effects. J Acoust Soc Am 2009;125:905-14.

42. Kälsch H, Hennig F, Moebus S, et al. Are air pollution and traffic noise independently associated with atherosclerosis: the Heinz Nixdorf Recall Study? Eur Heart J 2014;35: 853-60.

43. Gee GC, Payne-Sturges DC. Environmental health disparities: a framework integrating psychosocial and environmental concepts. Environ Health Perspect 2004;112:1645-53.

44. Morello-Frosch R, Shenassa ED. The environmental "Riskscape" and social inequality: implications for explaining maternal and child health disparities. Environ Health Perspect 2006;114:1150-3.

45. Baar J, Romppel M, Igel U, et al. The association between physical environment and health: indicating the direction of effects using German panel data. Int J Occup Environ Health 2016;22:1-6. [Epub ahead of print].

46. Flindell IH, Stallen PJ. Non-acoustical factors in environmental noise. Noise Health 1999;1:11-16.

47. Guski R. Personal and social variables as co-determinants of noise annoyance. Noise Health 1999;1:45-56. 